\title{
In vitro interaction of artemisinin derivatives or the fully synthetic peroxidic anti-malarial OZ277 with thapsigargin in Plasmodium falciparum strains
}

Oyindamola O Abiodun ${ }^{1,2}$, Reto Brun ${ }^{3,4}$ and Sergio Wittlin $3,4^{*}$

\begin{abstract}
Background: Semi-synthetic artemisinin derivatives are powerful peroxidic drugs in artemisinin-based combination therapy (ACT) recommended as first-line treatment of Plasmodium falciparum malaria in disease-endemic countries. Studies by Eckstein-Ludwig and co-workers showed both thapsigargin and artemisinin specifically inhibit the sarcoplasmic reticulum $\mathrm{Ca}^{2+}$-ATPase of Plasmodium falciparum (PfATP6). In the present study the type of interaction between thapsigargin and artemisinin derivatives as well as the ozonide OZ277 (RBX11160 or arterolane) was evaluated in parasite cultures. The latter compound is an adamantane-based peroxide and the first fully synthetic clinical candidate recently registered in India by Ranbaxy Laboratories Ltd. for anti-malarial combination therapy.

Methods: Drug interaction studies were performed using a previously described fixed ratio method and anti-malarial activity measured using the $\left[{ }^{3} \mathrm{H}\right]$ hypoxanthine incorporation assay.

Results: The sum 50\% and $90 \%$ fractional inhibitory concentration $\left(\sum \mathrm{FIC}_{50,90}\right.$ ) of the interaction of thapsigargin with OZ277, artemether or artesunate, against NF54 and K1 strains of $P$. falciparum ranged from 0.9 to 1.4.

Conclusion: The interaction of thapsigargin with OZ277, artesunate or artemether was additive, data consistent with previous observations indicating that activity of anti-malarial peroxides does not derive from reversible interactions with parasite targets.
\end{abstract}

Keywords: Thapsigargin, Artesunate, Artemether, OZ277, Plasmodium falciparum, Interaction study, Isobolograms

\section{Background}

Artemisinin is a sesquiterpene lactone isolated from $\mathrm{Ar}$ temisia annua. Semi-synthetic artemisinin derivatives are important endoperoxides in artemisinin-based combination therapy (ACT) recommended as first-line treatment of Plasmodium falciparum malaria in endemic countries. Despite their importance, the precise mechanism of action of this compound class is still under debate. The dominating view for all the peroxides (artemisinin derivatives and synthetic peroxides such as ozonides) is that they undergo reductive activation of

\footnotetext{
* Correspondence: sergio.wittlin@unibas.ch

${ }^{3}$ Parasite Chemotherapy Unit, Swiss Tropical and Public Health Institute, $\mathrm{CH}-4002$, Basel, Switzerland

${ }^{4}$ University of Basel, CH-4003, Basel, Switzerland

Full list of author information is available at the end of the article
}

the peroxide in the presence of ferrous iron released upon haemoglobin digestion within the parasite food vacuole [1]. This forms carbon centred radicals, which then alkylate key parasite proteins like haem and membrane-associated parasite proteins [2], one of which is the translationally controlled tumour protein (PfTCTP) [3] and another could be PfATP6, a SERCAtype $\mathrm{Ca}^{2+}$-ATPase [4]. Studies by Eckstein-Ludwig and co-workers showed that thapsigargin and artemisinin specifically inhibit PfATP6 with Ki values (half-maximum inhibition constants) of 146 and $162 \mathrm{nM}$, respectively [4]. In addition, artemisinin was shown to have a similar distribution in parasites when compared with thapsigargin, a specific inhibitor of PfATP6. Also, interaction between thapsigargin and artemisinin resulted in antagonism in cultured parasites. Interestingly, Crespo 
and co-workers reported that artemisinin and two novel epoxy-endoperoxides showed additive activity when used in combination with thapsigargin [5]. In the present study the type of interaction between thapsigargin and artemisinin derivatives as well as the ozonide OZ277 (RBx11160 or arterolane) [6,7] was evaluated in parasite cultures for the first time. A previous study to understand the mechanism(s) of action of OZ277 revealed that it inhibits PfATP6 with a Ki value of 7,700 nM; thus it is a much weaker inhibitor than artemisinin [8]. The study further showed that a fluorescent derivative of OZ277 displayed patterns of subcellular distribution different from that of artemisinin [8]. In order to shed more light on the mechanism of action of peroxidic anti-malarials vis à vis their interaction with PfATP6 in cultured parasites, the interaction of thapsigargin with OZ277 or the semi-synthetic artemisinin derivatives (artesunate and artemether) was evaluated in Plasmodium falciparum K1 and NF54 strains.

\section{Methods \\ Compounds}

The compounds used in this study were from the following sources: OZ277 tosylate (J L Vennerstrom, Nebraska, USA), artemether (Kunming Pharmaceuticals Corp, China), artesunate (Roche, Basel, Switzerland) and thapsigargin (Sigma, USA).

\section{In vitro anti-malarial activity}

Plasmodium falciparum strains NF54 (sensitive to all known anti-malarial drugs) and K1 (chloroquine/pyrimethamine resistant) were cultivated and maintained in continuous culture using standard techniques $[9,10]$. Initial concentrations for test compounds were $10 \mathrm{ng} / \mathrm{ml}$ for artemether, artesunate, OZ277 and 20,000 ng/ml for thapsigargin. Two-fold serial dilutions were done in hypoxanthine-free culture medium in 96-well plates over a 64 -fold range, the lowest being $0.16 \mathrm{ng} / \mathrm{ml}$ and $313 \mathrm{ng} /$ $\mathrm{ml}$ for the anti-malarial drugs and thapsigargin respectively. One hundred $\mu \mathrm{l}$ of an asynchronous parasite culture $(0.3 \%$ parasitaemia and $2.5 \%$ haematocrit $)$ was added to the drug solutions (100 $\mu \mathrm{l}$ volume) in 96-well plates. After 48 -hr incubation, 0.5 microCi of $\left[{ }^{3} \mathrm{H}\right]$ hypoxanthine (Anawa, Zürich, Switzerland) in $50 \mu \mathrm{l}$ of medium was added to each well and plates were incubated for an additional $24 \mathrm{hr}$. Parasites were harvested onto glass-fibre filters and radioactivity was counted using a Betaplate liquid scintillation counter (Wallac, Zurich). The results were recorded as counts per minute per well at each drug concentration and expressed as a percentage of the untreated controls. Fifty percent inhibitory concentrations $\left(\mathrm{IC}_{50}\right)$ were estimated by linear interpolation [11].

\section{In vitro drug interactions}

Drug interaction studies were performed using a modification of the fixed ratios method $[9,12]$. Initially, the $50 \%$ inhibitory concentration $\left(\mathrm{IC}_{50}\right)$ values of the individual test compounds were determined. Subsequently, the antimalarial compounds and thapsigargin were diluted with hypoxanthine-free culture medium to initial concentrations of 10 times the predetermined $\mathrm{IC}_{50}$ and the solutions combined in ratios of 1:3, 1:1, and 3:1. One hundred $\mu$ of the individual test compounds and mixtures were then introduced into the 96-well plates to give duplicate columns. The $\mathrm{IC}_{50}$ of the test compounds alone and in combination were determined as described above. For data interpretation, the $\mathrm{IC}_{50}$ or $\mathrm{IC}_{90}$ of the drugs in combination were expressed as fractions of the $\mathrm{IC}_{50}$ or $\mathrm{IC}_{90}$ of the individual drugs. These fractions were called fractional inhibitory concentrations (FIC) for drug A and for drug B, respectively.

\section{Interpretation of isobolograms}

Isobolograms were constructed by plotting the FIC of drug A $\left(\mathrm{FIC}_{\mathrm{A}}\right)$ against the FIC of drug $\mathrm{B}\left(\mathrm{FIC}_{\mathrm{B}}\right)$ for each of the three ratios, with concave curves indicating synergy, straight lines indicating addition and convex curves indicating antagonism. To obtain numeric values for the interactions, results were expressed as the sum FICs ( $\left.\sum F I C s\right)$ of the $\mathrm{FIC}_{\mathrm{A}}$ and $\mathrm{FIC}_{\mathrm{B}}$. Cutoff ranges were determined by mixing the same drug at various ratios and accounting for experimental variation. $\sum$ FIC values indicate the nature of the interactions as follows: $\sum \mathrm{FIC}<0.8$ is synergistic, $\sum$ FIC 0.8 to 1.4 is additive, $\sum$ FIC $>1.4$ is antagonistic. Mean $\sum$ FICs were used to classify the overall nature of the interaction.

\section{Results and discussion}

The susceptibility profile of OZ277, artesunate, artemether and thapsigargin was determined against both chloroquinesensitive and -resistant strains of $P$. falciparum (NF54 and K1) before embarking on the interaction studies. The two groups of peroxides displayed potent anti-malarial activity with $\mathrm{IC}_{50}$ and $\mathrm{IC}_{90}$ values ranging from 0.17 to $0.98 \mathrm{ng} / \mathrm{ml}$ and 0.42 to $1.9 \mathrm{ng} / \mathrm{ml}$ respectively (Table 1 ). In contrast

\begin{tabular}{|c|c|c|c|c|}
\hline \multirow[t]{4}{*}{ Compounds } & \multicolumn{4}{|c|}{ Inhibitory concentrations (ng/ml) } \\
\hline & \multirow{2}{*}{\multicolumn{2}{|c|}{$\frac{{ }^{+} P \text {. falciparum K1 }}{\text { (Mean } \pm \mathrm{SE})}$}} & \multirow{2}{*}{\multicolumn{2}{|c|}{$\begin{array}{c}{ }^{+} P . \text { falciparum NF54 } \\
\text { (Mean } \pm \text { SE) }\end{array}$}} \\
\hline & & & & \\
\hline & $\mathrm{IC}_{50}$ & $I C_{90}$ & $\mathrm{IC}_{50}$ & $I C_{90}$ \\
\hline Artesunate & $0.60 \pm 0.18$ & $1.8 \pm 0.1$ & $0.98 \pm 0.48$ & $1.9 \pm 1.1$ \\
\hline Artemether & $0.45 \pm 0.28$ & $0.80 \pm 0.34$ & $0.49 \pm 0.18$ & $0.98 \pm 0.27$ \\
\hline OZ277 & $0.17 \pm 0.03$ & $0.42 \pm 0.11$ & $0.82 \pm 0.09$ & $1.6 \pm 0.4$ \\
\hline Thapsigargin & $1612 \pm 140$ & $6850 \pm 730$ & $1940 \pm 433$ & $7455 \pm 2307$ \\
\hline
\end{tabular}

${ }^{+}$Data was obtained from three independent experiments. SE = standard error. 
Table 2 In vitro interaction of thapsigargin with OZ277 or semi-synthetic artemisinin derivatives against Plasmodium falciparum $\mathrm{K} 1$ and NF54 strains

\begin{tabular}{|c|c|c|c|c|c|c|c|c|c|}
\hline \multirow{3}{*}{$\begin{array}{l}\text { Thapsigargin } \\
\text { combined } \\
\text { with: }\end{array}$} & \multirow{3}{*}{$\begin{array}{l}P . \\
\text { falciparum } \\
\text { strains }\end{array}$} & \multicolumn{6}{|c|}{${ }^{+}\left(\sum \mathrm{FIC}\right) \pm$ Standard error at different ratio of drug combinations } & \multirow[b]{3}{*}{ mean $\sum \mathrm{FIC}_{50}{ }^{*}$} & \multirow[b]{3}{*}{ mean $\sum \mathrm{FIC}_{90}{ }^{*}$} \\
\hline & & \multicolumn{2}{|l|}{$1: 3$} & \multicolumn{2}{|l|}{$1: 1$} & \multicolumn{2}{|l|}{$3: 1$} & & \\
\hline & & $\sum \mathrm{FIC}_{50}$ & $\sum \mathrm{FIC}_{90}$ & $\sum \mathrm{FIC}_{50}$ & $\sum \mathrm{FIC}_{90}$ & $\sum \mathrm{FIC}_{50}$ & $\sum \mathrm{FIC}_{90}$ & & \\
\hline \multirow[t]{2}{*}{ OZ277 } & K1 & $1.0 \pm 0.0$ & $1.0 \pm 0.1$ & $1.1 \pm 0.0$ & $1.1 \pm 0.1$ & $1.4 \pm 0.1$ & $1.4 \pm 0.1$ & 1.2 & 1.2 \\
\hline & NF54 & $1.0 \pm 0.1$ & $1.0 \pm 0.0$ & $1.2 \pm 0.1$ & $0.9 \pm 0.0$ & $1.1 \pm 0.1$ & $0.9 \pm 0.0$ & 1.1 & 0.9 \\
\hline \multirow[t]{2}{*}{ Artemether } & K1 & $1.2 \pm 0.2$ & $1.1 \pm 0.0$ & $1.1 \pm 0.0$ & $1.0 \pm 0.1$ & $1.1 \pm 0.1$ & $0.9 \pm 0.1$ & 1.1 & 1.0 \\
\hline & NF54 & $1.1 \pm 0.1$ & $1.0 \pm 0.1$ & $0.9 \pm 0.1$ & $0.9 \pm 0.0$ & $1.2 \pm 0.1$ & $1.0 \pm 0.0$ & 1.1 & 1.0 \\
\hline \multirow[t]{2}{*}{ Artesunate } & K1 & $1.2 \pm 0.0$ & $1.2 \pm 0.0$ & $1.2 \pm 0.1$ & $1.2 \pm 0.2$ & $1.3 \pm 0.0$ & $1.1 \pm 0.1$ & 1.2 & 1.2 \\
\hline & NF54 & $1.1 \pm 0.0$ & $1.0 \pm 0.0$ & $1.1 \pm 0.1$ & $1.0 \pm 0.1$ & $1.0 \pm 0.0$ & $1.0 \pm 0.1$ & 1.1 & 1.0 \\
\hline
\end{tabular}

${ }^{+}$Data was obtained from three independent experiments. ${ }^{*} \mathrm{~m} \sum \mathrm{FICs}$ was used to classify the overall nature of the interaction which appears to be additive in this study.

thapsigargin showed anti-malarial activity that is approximately three to four log orders less potent $\left(\mathrm{IC}_{50}\right.$ range of $1,600-1,900 \mathrm{ng} / \mathrm{ml})$. Similar $\mathrm{IC}_{50}$ values for thapsigargin in parasite culture have also been reported previously [4].

Subsequently, the in vitro interaction of OZ277 and semi-synthetic artemisinin derivatives with thapsigargin against $P$. falciparum strains with different degrees of chloroquine sensitivity was evaluated. The employed fixed ratio isobologram method was described earlier by Fivelman and co-workers [12] and has been validated using a series of in vitro control combination assays [9]. These control assays include: in vitro interaction of artemether with pyrimethamine (proven antagonistic) $[13,14]$ and atovaquone with proguanil (proven synergistic) $[15,16]$. Interactions data were analysed at the $\mathrm{IC}_{50}$ and $\mathrm{IC}_{90}$ levels.

The sum 50\% and 90\% fractional inhibitory concentration $\left(\sum \mathrm{FIC}_{50,90}\right)$ of the interaction of thapsigargin with OZ277, artemether or artesunate, against both strains of P. falciparum ranged from 0.9 to 1.4 at the three ratios (1:3, 1:1 and 3:1 tested, Table 2, Additional file 1). This additive interaction is not unexpected based on the lack of antagonism observed between either artemisinin or OZ277 and their non-peroxide isosteres, data demonstrating that the activity of these drugs does not derive from reversible interactions with parasite targets [17]. Such additive interactions are also in line with data published by Crespo and co-workers [5], who demonstrated that artemisinin and two novel endoperoxides show additive activity when used in combination with thapsigargin. In contrast, data from Eckstein-Ludwig et al. [4] showed that the combination of artemisinin and thapsigargin was antagonistic ( $\sum$ FIC 1.5-5.0), which is possible in a scenario in which artemisinin and thapsigargin inhibit PfATP6 reversibly (non-covalent modification) [18].

\section{Conclusion}

The interaction of thapsigargin with OZ277, artesunate or artemether was additive, data consistent with previous observations indicating that activity of anti-malarial peroxides does not derive from reversible interactions with parasite targets.

\section{Additional file}

Additional file 1: Representative isobolograms of in vitro interactions of thapsigargin with $\mathrm{OZ277}$ or semi-synthetic artemisinins against Plasmodium falciparum.

\section{Abbreviations}

OZ277: Ozonide OZ277 (RBx11160 or arterolane); PfTCTP: Plasmodium falciparum translationally controlled tumour protein; PfATP6: Plasmodium falciparum Ca2+ - ATPase; $\sum$ FICs: sum of fractional inhibitory concentration; NF54: Plasmodium falciparum strain (sensitive to all known anti-malarial drugs); Kl: chloroquine/pyrimethamine resistant strain of Plasmodium falciparum; SERCA-type Ca ${ }^{2+}$-ATPase: Sarcoplasmic reticulum Ca2+ - ATPase; $\mathrm{FIC}_{A}$ : fractional inhibitory concentration (FIC) for drug $A ; \mathrm{FIC}_{B}$ : fractional inhibitory concentration (FIC) for drug B.

\section{Competing interests}

The authors declare that they have no competing interests.

\section{Authors' contributions}

OOA contributed to design, acquisition of data, analysis and interpretation of data. SW contributed to conception, design of the study and interpretation of data. OOA, RB and SW were involved in drafting the manuscript or revising it critically for important intellectual content. All authors read and approved the final manuscript.

\section{Acknowledgements}

OOA was supported at the Swiss Tropical and Public Health Institute, Basel, Switzerland by a training fellowship from Medicines for Malaria Venture, Geneva (Switzerland).

\section{Author details}

${ }^{1}$ Department of Pharmacology and Therapeutics, University of Ibadan, Ibadan, Nigeria. ${ }^{2}$ Malaria Research Laboratories, College of Medicine, University of Ibadan, Ibadan, Nigeria. ${ }^{3}$ Parasite Chemotherapy Unit, Swiss Tropical and Public Health Institute, $\mathrm{CH}-4002$, Basel, Switzerland. ${ }^{4}$ University of Basel, $\mathrm{CH}-4003$, Basel, Switzerland.

Received: 24 November 2012 Accepted: 16 January 2013 Published: 31 January 2013

\section{References}

1. Tilley L, Charman S, Vennerstrom JL: Semisynthetic artemisinin and synthetic peroxide antimalarials. In RSC Drug Discovery Series No. 14. Neglected Diseases and Drug Discovery. Edited by Mike P, Timothy NCW. 
Thomas Graham House, Science Park, Milton Road, Cambridge, CB4 OWF, UK: RSC Publishing; 2011:33-64. ISBN 9781849731928.

2. Asawamahasakda W, Ittarat I, Pu YM, Ziffer H, Meshnick SR: Reaction of antimalarial endoperoxides with specific parasite proteins. Antimicrob Agents Chemother 1994, 38:1854-1858.

3. Bhisutthibhan J, Pan XQ, Hossler PA, Walker DJ, Yowell CA, Carlton J, Dame $J R$, Meshnick SR: The Plasmodium falciparum translationally controlled tumor protein homolog and its reaction with the antimalarial drug artemisinin. J Biol Chem 1998, 273:16192-16198.

4. Eckstein-Ludwig U, Webb RJ, Van Goethem ID, East JM, Lee AG, Kimura M, O'Neill PM, Bray PG, Ward SA, Krishna S: Artemisinins target the SERCA of Plasmodium falciparum. Nature 2003, 424:957-961.

5. Crespo MP, Avery TD, Hanssen E, Fox E, Robinson TV, Valente P, Taylor DK Tilley L: Artemisinin and a series of novel endoperoxide antimalarials exert early effects on digestive vacuole morphology. Antimicrob Agents Chemother 2008, 52:98-109.

6. Vennerstrom JL, Arbe-Barnes S, Brun R, Charman SA, Chiu FC, Chollet J Dong Y, Dorn A, Hunziker D, Matile H, McIntosh K, Padmanilayam M, Santo Tomas J, Scheurer C, Scorneaux B, Tang Y, Urwyler H, Wittlin S, Charman WN: Identification of an antimalarial synthetic trioxolane drug development candidate. Nature 2004, 430:900-904.

7. Dong Y, Chollet J, Matile H, Charman SA, Chiu FC, Charman WN, Scorneaux B, Urwyler H, Santo Tomas J, Scheurer C, Snyder C, Dorn A, Wang X, Karle JM, Tang Y, Wittlin S, Brun R, Vennerstrom JL: Spiro and dispiro-1,2,4-trioxolanes as antimalarial peroxides: charting a workable structure-activity relationship using simple prototypes. J Med Chem 2005, 48:4953-4961.

8. Uhlemann AC, Wittlin S, Matile H, Bustamante LY, Krishna S: Mechanism of antimalarial action of the synthetic trioxolane RBX11160 (OZ277). Antimicrob Agents Chemother 2007, 51:667-672.

9. Snyder C, Chollet J, Santo-Tomas J, Scheurer C, Wittlin S: In vitro and in vivo interaction of synthetic peroxide RBx11160 (OZ277) with piperaquine in Plasmodium models. Exp Parasitol 2007, 115:296-300.

10. Trager W, Jensen JB: Human malaria parasites in continuous culture. Science 1976, 193:673-675.

11. Huber W, Koella J: A comparison of three methods of estimating EC50 in studies of drug resistance of malaria parasites. Acta Trop 1993, 55:257-261.

12. Fivelman QL, Adagu IS, Warhurst DC: Modified fixed-ratio isobologram method for studying in vitro interactions between atovaquone and proguanil or dihydroartemisinin against drug-resistant strains of Plasmodium falciparum. Antimicrob Agents Chemother 2004, 48:4097-4102.

13. Chawira AN, Warhurst DC: The effect of artemisinin combined with standard antimalarials against chloroquine-sensitive and chloroquine-resistant strains of Plasmodium falciparum in vitro. J Trop Med Hyg 1987, 90:1-8.

14. Fivelman QL, Walden JC, Smith PJ, Folb PI, Barnes Kl: The effect of artesunate combined with standard antimalarials against chloroquinesensitive and chloroquine-resistant strains of Plasmodium falciparum in vitro. Trans R Soc Trop Med Hyg 1999, 93:429-432.

15. Canfeld CJ, Pudney M, Gutteridge WE: Interactions of atovaquone with other antimalarial drugs against Plasmodium falciparum in vitro. Exp Parasitol 1995, 80:373-381.

16. Wiesner J, Henschker D, Hutchinson DB, Beck E, Jomaa H: In vitro and in vivo synergy of fosmidomycin, a novel antimalarial drug, with clindamycin. Antimicrob Agents Chemother 2002, 46:2889-2894.

17. Fügi MA, Wittlin S, Dong Y, Vennerstrom JL: Probing the antimalarial mechanism of artemisinin and OZ277 (arterolane) with nonperoxidic isosteres and nitroxyl radicals. Antimicrob Agents Chemother 2010, 54:1042-1046.

18. Chou T, Rideout DC: Synergism, Antagonism, and Potentiation in Chemotherapy: An Overview. In Synergism and Antagonism in Chemotherapy. Edited by Ting-Chao C, Darryl C. Waltham, Massachusetts: Academic Press Inc; 1991:3--53.

\section{doi:10.1186/1475-2875-12-43}

Cite this article as: Abiodun et al.: In vitro interaction of artemisinin derivatives or the fully synthetic peroxidic anti-malarial OZ277 with thapsigargin in Plasmodium falciparum strains. Malaria Journal 2013 12:43.

\section{Submit your next manuscript to BioMed Central and take full advantage of:}

- Convenient online submission

- Thorough peer review

- No space constraints or color figure charges

- Immediate publication on acceptance

- Inclusion in PubMed, CAS, Scopus and Google Scholar

- Research which is freely available for redistribution

Submit your manuscript at www.biomedcentral.com/submit
() Biomed Central 